\title{
Las políticas públicas: una construcción del valor público en la gobernabilidad
}

\author{
Dulfary Calderón Sánchez ${ }^{1}$
}

\section{Introducción}

Las políticas públicas constituyen una de las herramientas que le permite al Estado visibilizar las acciones encaminadas a desarrollar programas y proyectos que tienen como finalidad focalizar las demandas poblacionales con el objetivo de mitigar unas determinadas necesidades. Estas acciones están enmarcadas bajo un concepto de sinergia participativa a través de la gobernanza definida por Nohlen (2004) como la interacción entre gobernantes y gobernados, entre capacidades de Gobierno y demandas políticas del Gobierno.

El presente capítulo pretende abordar un panorama respecto a los elementos que constituyen la participación ciudadana como principal actor en la construcción de las políticas públicas, generando esa cohesión social que no debe remitirse solo a instrumentos cuantitativos o cualitativos, sino ser atendida como el reconocimiento de la identidad ciudadana y de la apropiación hacia las acciones del Estado; es decir, el valor público es aquello que el público valora (Blaug, 2006, p. 23).

1 Politóloga de la Universidad Nacional de Colombia. Magíster en Gestión y Política Pública de la Universidad de Chile. Profesora e investigadora de tiempo de la Facultad de Gobierno y Relaciones Internacionales en la Universidad Santo Tomás, Coordinadora del semillero y de la línea de Investigación política pública como eje de gobernabilidad y Gobernanza en el Estado. 
Las reflexiones que se presentan en las siguientes páginas parten de una premisa sobre que lo público es un asunto que concierne a toda la ciudadanía, ya que sus implicaciones financieras y su naturaleza social atañe aspectos de inclusión, participación, cohesión, eficacia y legitimidad.

Bajo esa tesitura, para abordar el contenido se estructuran tres temas principales. El primero corresponde a la participación ciudadana dentro de las políticas públicas, el segundo atañe al valor de lo público como un reconocimiento social y finalmente un tercer eje concatena los elementos para la construcción del valor de lo público en las políticas públicas.

De esta manera, se concluye con unas reflexiones finales que permiten concatenar la pertinencia de los temas en mención y generar una discusión en torno al valor de lo público.

\section{Las políticas públicas: un espacio de participación ciudadana}

Cuando se hace referencia al concepto de participación ciudadana, se tiende a construir el imaginario del ejercicio electoral que se lleva a cabo en un periodo determinado, y en el cual el Estado visibiliza los espacios para que las personas voten, limitando la percepción de lo que realmente implica ser partícipes en las decisiones institucionales. Para (Mujica, 2010, p. 143) es una forma de entender el ejercicio del poder donde los sujetos, entendiendo por tal a los ciudadanos, forman parte activa de los asuntos de interés público de forma igualitaria.

En efecto, dentro de las acciones que permiten generar visibilidad y legitimidad en los resultados de la implementación de las políticas públicas lo constituye los resultados que evalúan la eficacia, eficiencia y efectividad de estas. Sin embargo, el valor de lo público es el reconocimiento de la identidad ciudadana y de la apropiación hacia las acciones del Estado, en cuanto a que lo público concierne a toda la ciudadanía por su naturaleza que debe ser incluyente, participativa, eficaz y legítima.

En este sentido, la participación ciudadana puede ser concebida como el lugar donde interactuar las ideas, las estrategias y las necesidades de cada individuo para desarrollar acciones que involucren sus intereses particulares, en escenarios colectivos que actúen de manera conjunta:

Significa intervenir en los centros de gobiernos de una colectividad, participar en sus decisiones en la vida colectiva, de la administración de sus recursos, del modo como se distribuye sus costos y beneficios. Así los ciudadanos poco a poco tomarán parte de las decisiones que tomen sus gobernantes. El propósito es lograr 
que la población influya sobre las políticas y decisiones públicas, para ello se hace necesario institucionalizar mecanismos, procesos y organismos a través de una normatividad legal. (Merino, 1995, p. 11)

De esta manera, el Estado converge en diferentes acciones para proporcionar espacios de participación ciudadana ofreciendo instancias y actores que establezcan normas para la toma de decisiones. Al respecto, Cunill (1995) señala que no obstante el discurso como un elemento que favorece la participación ciudadana, aún no ha podido encontrar las condiciones propicias que permitan un ejercicio efectivo en los espacios gubernamentales, teniendo en cuenta su vinculación con la posibilidad de contribuir a su propia democratización.

Sin embargo, como lo menciona más adelanta el autor en el texto, se trata de adoptar la participación desde la institucionalidad asumiendo la esfera pública como el lugar donde deben converger los temas de intereses. Para ello una democratización de los espacios ciudadanos permite ser partícipes en la toma de decisiones, en este caso enfocadas en las políticas públicas.

\begin{abstract}
Existen diversas maneras de entender la participación de la sociedad en las políticas públicas: para unos -ciertamente los menos-, esta se da cuando, vía la emisión del sufragio, los representantes delegados por la ciudadanía toman las decisiones en nombre de sus representados; para otros -hasta ahora los más-, la participación ciudadana en las políticas implica que los decisores tomen en cuenta las preferencias y las opiniones de los ciudadanos para que, por este solo hecho, el público se convierta en actor de los procesos de formulación de políticas (Canto, 2008, p. 2).
\end{abstract}

Estos procesos mencionados permiten generar gobernabilidad en las acciones, gestión y resultados para subsanar las necesidades sociales que en ocasiones pasan a ser demandas urgentes por resolver. De esta manera, la esfera pública termina asumiendo el rol de la participación ciudadana al ser tomador de decisiones, quizás porque se desconoce el espacio o porque simplemente a la ciudadanía no le importa el proceso en la toma de decisión, sino un resultado que finalmente subsane o genere una solución, a mediano o corto plazo, a su condición demandante.

En el caso de las políticas públicas, la participación ciudadana debe ser un factor inherente en la toma de decisiones y durante el proceso que involucra la implementación de los proyectos, ya que de allí parte la focalización de sus necesidades en resultados esperados y que estén inmersos en las lógicas de desarrollo social.

De manera similar, durante el proceso de seguimiento y evaluación, la participación ciudadana debe ser central porque los resultados esperados de la política pública 
permiten conocer la trazabilidad temporal de las acciones impuestas por los actores gubernamentales como resultado de la ejecución de la misma.

Para ello es importante el papel de los ciudadanos ya que con el fin de optimizar la participación ciudadana en estos espacios de reconocimiento social, deben asumir un papel de veedores en la gestión institucional realizada que permita una articulación en la construcción de procesos inherentes de ciudadanía.

En los escenarios de participación ciudadana, concebidos desde la esfera pública, la dimensión interpretativa de la política para Roth parte de tres definiciones:

Figura 1. Interpretaciones de la política, según Roth

\begin{tabular}{|l|l|}
\hline Polity & Concebida como el ámbito del gobierno de las sociedades humanas. \\
\hline La política & Como la actividad de organización y lucha por el control del poder \\
\hline Policy & $\begin{array}{l}\text { Como designación de los propósitos y programas de las autoridades } \\
\text { públicas. }\end{array}$ \\
\hline
\end{tabular}

Fuente: (Roth, 2002)

Se puede inferir de las interpretaciones anteriores, que dan cuenta de unos elementos articuladores en la construcción de participación ciudadana, la polity como el espacio de inmersión donde el Gobierno permite a los ciudadanos ser partícipes, consultores y ejecutores en la toma de decisiones; la politics como un medio donde se debaten los intereses individuales que por la misma naturaleza de la dinámica se transforman en intereses colectivos siendo una lucha por el control de las acciones entre el Gobierno y los ciudadanos; y finalmente la policy como el resultado de las decisiones consensuadas aplicadas a los programas encaminadas a subsanar las demandas presentadas.

Lo anterior en tanto que la sinergia de los tres escenarios constituyen un fortalecimiento de la participación como construcción social del ciudadano definido como:

El proceso de la construcción de una ciudadanía de derechos es el que permite el surgimiento de la identidad pública y como tal de una identidad política; son las relaciones con los demás ciudadanos y con el Estado las que autorizan a una persona o a un colectivo de personas a establecer interlocución legítima con las instituciones. La ciudadanía es entonces el lugar de intersección o encuentro de los ciudadanos entre sí, en la dinámica de auto-reconocimiento de sus propios derechos y de los de los demás, así como de estos sujetos de derechos con la institucionalidad estatal (Vicepresidencia de la Republica de Colombia, 2009, p. 17). 
Como lo menciona el observatorio, para que coexista un autoreconocimiento entre la institucionalidad del Estado y los derechos humanos de los individuos se debe generar una identidad de las personas, como sujetas de derechos y deberes, que le permita dar una visibilidad sobre esa restitución y exigibilidad que compete una serie de garantías institucionales.

En efecto, Colombia cuenta con un marco normativo que permite a los ciudadanos ser partícipes en el control interno, administrativo, ejercicios de control político, de acciones populares y de veedurías entre otros hacia las instituciones del Estado.

Sin embargo, cuando se habla de las garantías para la participación como derecho no solo se remite al espacio de la esfera pública, sino implica una interacción social, comunitaria, política y ciudadana que permite un ejercicio de organización entre los sujetos.

Para autores como Guillen, participar no es solo colaborar ni opinar sobre una determinada actuación. Participar supone una determinada actuación. Participar supone un plus de voluntad de intervención, un sentimiento de pertenencia colectivo, a una ciudad en este caso. Es por ello que pese al impacto de los canales diseñados por los poderes públicos, no puede olvidar la importancia de la vida asociativa en las ciudades y sus posibilidades, que pueden ir más allá de una participación limitada a la emisión de opiniones al respecto a las actuaciones administrativas (Guillen, 2009, p. 186).

En suma, deben cohesionarse la participación ciudadana a partir de tres factores necesarios para una gobernabilidad y gobernanza entre actores que permita fortalecer las redes de participación ciudadana, como lo ilustra la tabla 1.

De manera que esta articulación que se genera entre la esfera pública y la esfera privada, en las diferentes dinámicas de participación ciudadana, permite aportar confianza en la gobernanza entre los actores, así como una construcción sinérgica en la toma de decisiones de manera directa para el actuar del Estado.

De lo anterior se deriva que el institucionalismo estatal parte de los factores que componen esos espacios en los que la gobernanza entre los actores y las instancias permiten generar una serie de procesos que legitiman los ciclos de las políticas públicas como una herramienta de inclusión participativa. En este sentido, Aguilar lo referencia como:

a) Un conjunto (secuencia, sistema, ciclo) de acciones, estructuradas en modo intencional y causal, que se orientan a realizar objetivos considerados de valor para la sociedad o a resolver problemas cuya solución es considerada de interés o beneficio público; b) acciones cuya intencionalidad y causalidad han sido definidas por la interlocución que ha tenido lugar entre el Gobierno y los sectores de la ciudadanía; c) acciones que han sido decididas por autoridades públicas 
legítimas; d) acciones que son ejecutadas por actores gubernamentales o por estos en asociación con actores sociales (económicos, civiles), y e) que dan origen o formen un patrón de comportamiento del Gobierno y la sociedad (Aguilar, 2009, p. 14).

Tabla 1. Razones para fortalecer la participación ciudadana (fuente adaptación de OECD)

\begin{tabular}{|c|c|}
\hline Políticas públicas de mejor calidad & $\begin{array}{l}\text { El fortalecimiento de las relaciones entre instituciones públi- } \\
\text { cas y ciudadanos incita a estos últimos a dedicar tiempo y } \\
\text { esfuerzo a asuntos de interés público. Su contribución es un } \\
\text { recurso que debe ser valorizado y aprovechado. La informa- } \\
\text { ción, la consulta y la participación activa proporcionan a la } \\
\text { administración pública una mejor base para la elaboración } \\
\text { de políticas públicas, lo que le permite convertirse en una } \\
\text { organización en constante aprendizaje. Simultáneamente, } \\
\text { esto garantiza una implementación más eficaz de dichas } \\
\text { políticas, en la medida en que los ciudadanos están familia- } \\
\text { rizados con ellas, al participar en su elaboración. }\end{array}$ \\
\hline $\begin{array}{l}\text { Confianza acrecentada en las institu- } \\
\text { ciones públicas }\end{array}$ & $\begin{array}{l}\text { La información, la consulta y la participación activa propor- } \\
\text { cionan a los ciudadanos una oportunidad para familiarizarse } \\
\text { con los proyectos de la administración pública para dar a } \\
\text { conocer su opinión y contribuir en la toma de decisiones. } \\
\text { Este involucramiento favorece la aceptación de las opciones } \\
\text { políticas resultantes. La administración pública da prueba de } \\
\text { apertura, lo que la vuelve más fiable ante los ojos del ciuda- } \\
\text { dano, poseedor de la soberanía en un régimen democrático. } \\
\text { Al suscitar confianza en los poderes públicos y al mejorar } \\
\text { la calidad de las políticas públicas, el fortalecimiento de las } \\
\text { relaciones entre las instituciones públicas y los ciudadanos } \\
\text { aumenta la legitimidad del Gobierno. }\end{array}$ \\
\hline Democracia más fuerte & $\begin{array}{l}\text { La información, la consulta y la participación activa incre- } \\
\text { mentan la transparencia de la administración pública y la } \\
\text { vuelven responsable. El fortalecimiento de las relaciones } \\
\text { entre la administración pública y los ciudadanos incentiva } \\
\text { una ciudadanía activa y favorece su arraigo en la sociedad. } \\
\text { La democracia participativa complementa y fortalecen } \\
\text { la democracia en su totalidad. Claridad en sus políticas } \\
\text { públicas al ser parte de una deliberación razonable para } \\
\text { construir su proyecto de nación que asegure un nivel de vida } \\
\text { adecuado. }\end{array}$ \\
\hline
\end{tabular}

Fuente: (Guillen, 2009). Elaboración del autor. 
No obstante, el autor deslumbra una forma ideal de participación ciudadana en la que las personas encuentran un espacio para legitimar las demandas sociales. Estas son vistas en ocasiones como una necesidad imperante de mejorar una situación en la que se encuentra afectado un bien común. Pensar en una formulación e implementación de estas es pensar en desarrollar un proceso de inscripción en la agenda pública, una toma de decisión y una implementación donde sean partícipes el Estado y la sociedad civil como agentes activos en un marco de gobernabilidad.

Para (Uvalle, 2005) lo público de las políticas deviene del modo en que los ciudadanos participan en las etapas que comprenden la definición, la elaboración, la implementación y la evaluación. Cada uno de los procesos mencionados refiere a una atención especial de los ciudadanos; por ejemplo, la toma de decisión constituye uno de los ejes para el desarrollo del diseño ya que allí es donde se determina cuáles son los temas que deben estar direccionando los programas, planes o proyectos enfocados a una población, así mismo se plantean cuáles deben ser los procesos a seguir para consolidar las metas estipuladas en el tiempo determinado.

En este contexto, si durante la toma de decisiones las consecuencias del diseño en una política pública dan cuenta del resultado de esa convergencia de intereses colectivos, entonces, ¿por qué en algunos temas cuentan con mayor participación ciudadana y otros no? Quizás una posible respuesta se deriva del modelo de inscripción en la agenda pública, lo cuales determinan elementos como:

- Los problemas crónicos. Se caracterizan por ser un tipo de problemas considerados prioritarios por una alta proporción de la población, que forman parte de la agenda desde un punto en el tiempo difícil de identificar pero, de cualquier modo, bastante lejano, y que integran la agenda de manera permanente (...).

- Los temas intermitentes. Por lo general suelen recibir una atención media o baja por parte del público. Se trata de temas que forman parte de la agenda también desde hace mucho tiempo, pero cuya presencia es discontinua (...).

- Los temas nuevos. Se hace referencia a temas de reciente aparición y de los que, por tanto, conocemos aproximadamente el momento en que han comenzado a atraer la atención del público (...) (Carrillo \& Tamayo, 2005, p. 665).

A su vez, también se puede inferir en los llamados ciclos de atención, los cuales permiten la interacción de los actores para mantener latente el problema o la demanda en la agenda pública, visibilizando esa necesidad de demandar unas posibles soluciones. En este sentido, para (Roth, 2002) es importante la persuasión y las estrategias que los actores desarrollen con el fin de estipular su posición frente 
a un tema determinado, siendo indispensable la dinámica que se origine entre la administración pública, la sociedad y los destinatarios.

No obstante, aunque exista un modelo de construcción ciudadana en las decisiones públicas se debe tener en la cuenta que existen limitaciones intra y/o extrarrégimen que condicionan la voluntad del individuo para ser partícipes en la inscripción de las demandas a la agenda pública y en los ciclos de atención que son un factor para la viabilidad de las políticas públicas.

Tabla 2. Limitaciones intra y extrarrégimen a la participación ciudadana

\begin{tabular}{|l|l|}
\hline \multicolumn{2}{|c|}{ Limitaciones a la participación ciudadana } \\
\hline Régimen político y reglas formales & Extrarrégimen (sociedad) \\
\hline Elecciones cuestionadas & Desconfianza hacia leyes e instituciones \\
\hline $\begin{array}{l}\text { Falta de certeza, legalidad, imparcialidad y } \\
\text { equidad. }\end{array}$ & Desconfianza en los demás \\
\hline Discrecionalidad & $\begin{array}{l}\text { Intolerancia hacia la diferencia y la pluralidad } \\
\text { (en ideas, creencias e identidades) }\end{array}$ \\
\hline Falta de transparencia y rendición de cuentas. & $\begin{array}{l}\text { Discriminación (por edad, género, sexo, raza, } \\
\text { religión o ideas políticas) }\end{array}$ \\
\hline Fallas en sistema de contrapesos & Escasez de asociaciones y grupos altruistas \\
\hline $\begin{array}{l}\text { Fallas en el sistema judicial: parcialidad, lentitud } \\
\text { e inequidad }\end{array}$ & $\begin{array}{l}\text { Ausencia de cooperación para solucionar proble- } \\
\text { mas colectivos }\end{array}$ \\
\hline Congreso capturado por intereses partidarios & $\begin{array}{l}\text { Prácticas autoritarias al interior de familias, } \\
\text { escuelas y empresas }\end{array}$ \\
\hline $\begin{array}{l}\text { Ausencia de mecanismos para garantizar ejerci- } \\
\text { cio de derechos }\end{array}$ & $\begin{array}{l}\text { Ausencia de deliberación social pública sobre } \\
\text { asuntos colectivos }\end{array}$ \\
\hline $\begin{array}{l}\text { Ausencia del reconocimiento constitucional del } \\
\text { derecho ciudadano a participar en las decisiones } \\
\text { y asuntos públicos }\end{array}$ & $\begin{array}{l}\text { Ausencia de medios de comunicación indepen- } \\
\text { dientes, plurales y abiertos a la sociedad }\end{array}$ \\
\hline $\begin{array}{l}\text { Mecanismos de consulta y participación social } \\
\text { ausentes, insuficientes y/o sin efecto vinculatorio }\end{array}$ & $\begin{array}{l}\text { Relaciones sociales supeditadas a maximizar } \\
\text { interés individual (costo/ beneficio) }\end{array}$ \\
\hline $\begin{array}{l}\text { Criminalización/judicialización de movilizacio- } \\
\text { nes y protestas sociales }\end{array}$ & $\begin{array}{l}\text { Apropiación y/o mercantilización de espacios y } \\
\text { bienes públicos por grupos de poder político y/o } \\
\text { económico }\end{array}$ \\
\hline
\end{tabular}

Fuente: (Villarreal, 2009). Elaboración propia del autor.

Para un reconocimiento de la participación ciudadana en las decisiones del Estado bajo las premisas de las limitaciones mencionadas anteriormente, es importante reconocer el valor de lo público; es decir, las decisiones no solo competen al Estado sino a los ciudadanos, quienes son los que aportan a través de sus impuestos u otros 
tipos de recaudos a la financiación de los programas. En tanto que, cuando se habla de lo público, implica la existencia de unos recursos públicos.

Ahora bien, una política pública no solo constituye un reconocimiento del valor de lo público bajo una premisa de participación ciudadana, sino que debe estar acorde a las dinámicas locales, en las que la inclusión de las demandas están expuestas a la implementación y duración en los respectivos programas territoriales, lo cual da identidad social a las acciones.

\section{El valor de lo público: un reconocimiento social}

Lo público, desde la esfera estatal, puede definirse como el espacio donde deben converger los intereses colectivos y donde la sociedad cuenta con escenarios para manifestar la institucionalidad del Estado como garante del cumplimiento de estos escenarios. Desde el ámbito de las políticas públicas, es pensar en un reconocimiento del valor público en el que esté implícito la inserción de una cultura que integre conceptos de apropiación y aprobación de la ciudadanía, con miras a un empoderamiento de las acciones estatales a partir de los espacios participativos como sinergia para la gobernabilidad.

En este caso el valor público es tomado no desde un concepto netamente económico, sino como un espacio que permite desarrollar una identidad, como sociedad, de una situación que concierne a todos, de una pluralidad de derechos y deberes, de un bien que se necesita resguardar bajo un marco de garantías constitucionales y estatales. Para Bertucci, el concepto de valor público:

Asume que la gente tiene la capacidad y la libertad para expresar sus preferencias respecto a las actividades y resultados de la Administración Pública. También asume que las Administraciones Públicas tienen la voluntad y la capacidad para acomodar sus objetivos a las preferencias ciudadanas; y más que eso, asume que al entregar el valor público requerido, la gente estará dispuesta a pagar por él con dinero, con el voto u ofreciendo su tiempo para colaborar con el Gobierno (Bertucci, 2005).

Precisamente, como lo menciona el autor, al existir ese valor de lo público estos elementos permiten generar socialmente un resguardo e interés por la gestión pública dado a que la financiación de los bienes y servicios provienen de los recursos aportados por los ciudadanos, quienes subsidian la administración pública y pagan a los funcionarios por su trabajo, así como las acciones que ejecuta el Estado para desarrollar proyectos, planes o programas sociales encaminados al crecimiento de la calidad de vida de los ciudadanos. 
Estas responsabilidades deben ser tomadas por los ciudadanos como el valor de lo público y permite visibilizar acciones del Estado como lo constituye la rendición de cuentas. Esta suministra a los ciudadanos la información referente a cómo se está invertido el dinero, el porcentaje de efectividad, eficiencia y la gestión de las entidades hacia la optimización de los recursos, así como la credibilidad institucional sobre sus alcances en la administración pública y que genere en el ciudadano una coherencia del resultado esperado.

Desde un enfoque integral para la gestión de políticas, el valor público es visto como los beneficios derivados de los servicios que presta el Estado a los ciudadanos a través de diferentes acciones como los programas, las políticas y los planes, entre otros, que están enfocados a brindar un servicio accesible a la sociedad (Conejero citando a Constable).

La propuesta Central de Moore consiste en que los recursos públicos deben ser utilizados para incrementar el valor de la misma forma que se crea valor en el sector privado. Teniendo en consideración que el valor de lo público debe ir más allá de un enfoque de impactos monetarios y debe incluir beneficios sociales percibidos por los ciudadanos. Una perspectiva más general considera al valor público como un enfoque integral para pensar en la gestión pública y en la mejora continua en los servicios públicos (Conejero, 2014, p. 9).

Cuando existe un reconocimiento del valor de lo público por parte de la ciudadanía, se ejerce una mayor veeduría sobre la intervención del Estado. Esto supone que se perciban, como lo menciona Conejero, unos beneficios ciudadanos que fortalecen la gobernabilidad vista como las acciones de las instituciones que componen las dinámicas entre la sociedad y el Estado:

Debe ser entendida como "un estado de equilibrio dinámico entre el nivel de las demandas societales y la capacidad del sistema político (Estado/Gobierno) para responderlas de manera legítima y eficaz". Ello permite superar una lectura dicotómica (gobernabilidad versus ingobernabilidad) y analizar grados y niveles de gobernabilidad involucrando en la definición una "serie de 'acuerdos' básicos entre las élites dirigentes (...) en torno a tres ámbitos principales (...) el nivel de la cultura política (...) el nivel de las reglas e instituciones del juego político (... y) acuerdos en torno al papel del Estado y sus políticas públicas estratégicas". (Camou, 2001, p. 36)

Por consiguiente, uno de los elementos para la gobernabilidad parte de la importancia que tienen las políticas públicas como elemento estratégico ya que permiten dar cuenta del valor de lo público, por su diseño, gestión, implementación y evaluación, identificando la sinergia en la participación ciudadana hacia la 
administración pública. Esta como un escenario de decisiones y ejecución de los recursos públicos.

De ello resulta necesario admitir que si las instituciones dan cuenta la gestión pública, entonces ¿cómo involucrar a la ciudadanía para que sea participe de esa construcción del valor de lo público? ¿Por qué algunos temas son de mayor interés que otros? ¿Cuál debe ser la motivación de las instituciones por involucrar a los ciudadanos en la toma de decisión?

Una posible respuesta puede remitirse a los mecanismos de visibilización que utiliza el Estado donde la participación ciudadana no puede concentrarse únicamente al ejercicio electoral, sino debe partir de la importancia en las acciones institucionales hacia a los ciudadanos, que permita percibir beneficios en un corto, mediano o largo plazo a la demandas, sin descuidar las necesidades que involucra una capacidad gubernamental que compete una serie de políticas estatales previstas en su estructura gubernamental.

\section{Hacia la construcción de un valor de lo público en las políticas públicas}

Las políticas públicas, desde la gobernabilidad, son concebidas como uno de los elementos que permite dar legitimidad a las acciones administrativas que emana el Estado, tendientes a consolidar una confianza entre los ciudadanos y las instituciones políticas permitiendo dar visibilidad a los proyectos, programas $y / 0$ planes enmarcados en un contexto de desarrollo humano.

Por ende, el Estado constituye esa sinergia dinámica entre los ciudadanos y las instituciones a partir de la consolidación de resultados que deben constituir uno de los elementos esenciales para el desarrollo social de la esfera pública y privada, en un escenario de reciprocidad entre el impacto recibido por los ciudadanos y el aporte de los mismos hacia la visibilidad de estas directrices.

A su vez, esta articulación no solo es necesaria para un reconocimiento del valor de lo público visto como ese espacio de la ciudadanía, sino debe soportarse a partir del conocimiento de la gestión administrativa en las instituciones cuyo propósito debe ser visible en la sociedad. Para ello la socialización, la divulgación y la promoción que las organizaciones gubernamentales deben hacer hacia la sociedad infiere en la credibilidad y confianza del ciudadano por el Estado y específicamente cuando se habla de políticas públicas.

Sin embargo sucede que este diseño de políticas públicas no corresponde a esas necesidades demandadas donde puede haber carencias sociales cuya satisfacción 
no es solicitada por uno o más sectores. La preservación del ambiente puede ser un ejemplo o la calidad institucional (IDD-Lat, 2011). Han sido y siguen siendo necesidades a satisfacer. Sin embargo, no en todas las épocas ni en todos los lugares se demandan socialmente. La educación vial puede ser otro ejemplo o la prevención de la salud, etc. (Graglia J. , 2012, p. 36).

Por consiguiente pueden pasar dos situaciones: la primera corresponde al desconocimiento de los ciudadanos frente a la existencia o el funcionamiento de una política pública determinada ya sea por la falta de información institucional o por la forma en que la política se imparte a los beneficiarios. De manera similar también puede influir la saturación de programas gubernamentales en torno al mismo problema, por lo que tiende a confundir al ciudadano sobre la existencia de nuevas políticas, por ejemplo, en el tema de seguridad alimentaria en Colombia se presenta una duplicidad de programas, lo cual genera en la población beneficiaria un doble asistencialismo; por un lado, los bonos dados por el Gobierno nacional, y por otro, los comedores comunitarios que tiene el distrito capital.

De modo semejante, en un segundo escenario, el programa implementado no corresponde a las demandas presentadas por la población, generando que el interés de los ciudadanos tienda a ser minimizado ya que al no sentirse correspondido en las respuestas que las instituciones implementan, su interés tiende a ser nulo. Por ende, el valor de lo público y la participación en los procesos de seguimiento e implementación de la política pública es inexistente. De esta manera, la centralidad de las políticas que converge en los derechos humanos tiende a desdibujar el concepto primordial que corresponde al individuo como sujetos de derechos humanos.

En consecuencia, cuando se contextualiza un Estado Social de Derecho como se consagra en la Constitución Política colombiana, se debe hacer referencia a un Estado como garante de los derechos humanos, unos "sociales de derecho" que pasan por la especificación, expansión y profundización de los derechos humanos con miras a garantizar su ejercicio por todos los sectores de la población (Güendel, 2000).

Estos ejercicios de participación ciudadana son los que permiten generar esas dimensiones en el ámbito social y los que permiten dar ese valor de lo público, basado en un enfoque de derechos que estén inmersas en las políticas públicas, considerando que su carácter integral no es excluyente ni desigual y permite fomentar la toma de decisiones que favorezcan la esfera social y una cobertura con miras a la eficiencia y eficacia. 
Tabla 3. Algunas dimensiones para el análisis de las políticas públicas en el ámbito social desde el enfoque de derechos humanos

\begin{tabular}{|c|c|}
\hline Dimensiones & Enfoque de derechos \\
\hline Objetivos & $\begin{array}{l}\text { Adopción explícita del marco normativo internacional de los } \\
\text { derechos humanos. } \\
\text { Reconocimiento e integración social de las "ciudadanías } \\
\text { específicas" }\end{array}$ \\
\hline Estrategia & $\begin{array}{l}\text { - Orientación hacia el cumplimiento de las obligaciones de } \\
\text { respeto, protección y cumplimiento de los derechos humanos. } \\
\text { Determinación de metas inmediatas y puntos de referencia para } \\
\text { el cumplimiento progresivo de los derechos. } \\
\text { - Reconocimiento del principio de integralidad como base para } \\
\text { un abordaje global y en conjunto de los derechos humanos. }\end{array}$ \\
\hline Cobertura/destinatarios & $\begin{array}{l}\text { - Universal, combinada con acciones focalizadas para fortalecer } \\
\text { la equidad. }\end{array}$ \\
\hline Foco de preocupación & $\begin{array}{l}\text { - El sujeto reflexivo y empoderado como centro de la política } \\
\text { pública. } \\
\text { - Lo público local como espacio para el ejercicio de la ciudadanía. }\end{array}$ \\
\hline Institucionalidad & $\begin{array}{l}\text { - Énfasis en la integralidad, en la multisectorialidad y en la redefi- } \\
\text { nición de prioridades. } \\
\text { - Desarrollo de la información social desagregada, oportuna y de } \\
\text { calidad como mecanismo de visibilización de los déficit. } \\
\text { - Garantía del acceso a la información oficial de manera } \\
\text { transparente. }\end{array}$ \\
\hline Dimensión política & $\begin{array}{l}\text { - Reconocimiento de la necesidad de consensos políticos básicos } \\
\text { para hacer sostenible la política social y establecer prioridades } \\
\text { compartidas. } \\
\text { - Empoderamiento y ciudadanía como dimensiones políticas de } \\
\text { la acción social. } \\
\text { - Mecanismos accesibles y transparentes de exigibilidad de } \\
\text { responsabilidades. }\end{array}$ \\
\hline Gestión y participación & $\begin{array}{l}\text { - La participación activa y documentada es fundamental como } \\
\text { mecanismo base para el empoderamiento social y el fortaleci- } \\
\text { miento de la institucionalidad pública. } \\
\text { - Basado en los principios de factibilidad económica y equidad } \\
\text { social. } \\
\text { - Gasto social y política fiscal como instrumentos privilegiados de } \\
\text { las políticas públicas }\end{array}$ \\
\hline
\end{tabular}




\begin{tabular}{|l|l|}
\hline \multicolumn{1}{|c|}{ Dimensiones } & \multicolumn{1}{c|}{ Enfoque de derechos } \\
\hline Financiamiento & $\begin{array}{l}\text { - Garante de derechos fundamentales que aseguren el acceso a } \\
\text { umbrales de bienestar necesarios para la integración social. } \\
\text { - Principal titular de deberes, siendo la instancia ante la cual se } \\
\text { afirman los derechos humanos. }\end{array}$ \\
\hline Sociedad/Comunidades & $\begin{array}{l}\text { - Ejercen sus derechos. } \\
\text { - Inciden con su participación en los procesos de toma de } \\
\text { decisiones. } \\
\text { - Exigen la reconstitución de los derechos vulnerados a través de } \\
\text { mecanismos socialmente establecidos y reconocidos. } \\
\text { - Se conciben como un tejido formado por multiplicidad de redes } \\
\text { generadoras de lazos de pertenencia. }\end{array}$ \\
\hline Empresariado & $\begin{array}{l}\text { - Produce bienes y servicios sin lesionar los derechos de terceros. } \\
\text { - Como iniciativa privada coadyuva en la materialización de los } \\
\text { planes de desarrollo. }\end{array}$ \\
\hline Organizaciones No & $\begin{array}{l}\text { - Proveen servicios como entidades públicas no estatales sin } \\
\text { afectar el papel del Estado como rector en la formulación de las } \\
\text { políticas y su financiamiento. }\end{array}$ \\
\hline Gubernamentales & $\begin{array}{l}\text { - Asistencia técnica y de cualquier otra índole en el marco de sus } \\
\text { ámbitos de acción para promover y colaborar en la implementa- } \\
\text { ción del enfoque de derechos. }\end{array}$ \\
\hline Agencias de cooperación
\end{tabular}

Fuentes: Barahona, 2004; Calderón, 2000; Güendel, 2007; Pírez, 1995; Sottoli, 2002; UNFPA, 2006.

En tal caso, estas dimensiones presentadas corresponden precisamente a ese escenario social donde el ciudadano debe identificar cuál es su papel dentro de la legitimidad de una gobernanza; de allí parte una fundamentación sobre la inserción del individuo en el espacio estatal en el que el enfoque de derechos debe ser el eje central para la construcción de la confianza en las directrices del Estado.

Por consiguiente, se deben desarrollar los parámetros de cómo esa interacción del Estado permite establecer lineamientos acordes a las necesidades o demandas estipuladas por quienes habitan los territorios; es decir, los resultados esperados por los ciudadanos no concuerdan con las expectativas y tienden a ser más de las instituciones (quizás por cumplir).

En efecto, uno de los elementos clave para generar el valor público en los ciudadanos corresponde al empoderamiento social ya que permite una participación y una democratización de los espacios, en la que el ciudadano es protagonista de las acciones que se encaminan al fortalecimiento de su desarrollo individual y comunitario como se observa en la siguiente gráfica. 
Figura 2. Las dimensiones del empoderamiento y sus interrelaciones

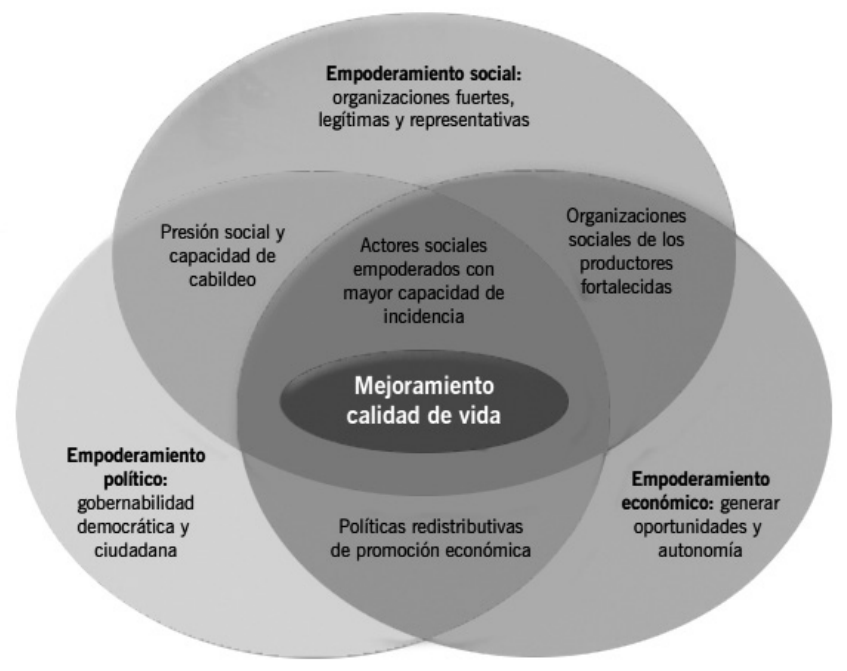

Fuente: Asocam. Empoderamiento: conceptos y orientaciones.

Secretaria Técnica, Quito, octubre 2007.

Estas dimensiones presentadas permiten identificar tres factores sinérgicos que componen la esfera estatal y que están inmersos en las políticas públicas, organizando los actores sociales con una capacidad de mayor incidencia en las organizaciones sociales donde se identifican elementos identitarios que les permite actuar. Así mismo el mejoramiento en la calidad de vida debe ser el centro de los ciudadanos, quienes son los beneficiarios de las respuestas estatales a partir de esos procesos de planificación.

Giménez y Valente (2010) mencionan que los procesos de planificación requieren de la participación y el empoderamiento de las comunidades a través de sujetos documentados, reflexivos y críticos dispuestos a involucrarse activamente en la resolución de las problemáticas presentes en su entorno, que ejecuten acciones en pro de la defensa de sus derechos partiendo de la necesidad de consolidar un bien común éste definido como:

El concepto de bien común incluye, además de la realización del bien personal de los agentes, unos resultados sociales en términos de igualdad, nivelación de las condiciones de partida y provisión de un Estado de bienestar universal. El mercado es el ámbito de la eficiencia y de la creación de riqueza, en tanto que el Estado es el de 
la solidaridad y la redistribución (...) El bien común acaba siendo, pues el proceso por el que los individuos acuerdan formar una sociedad que consideren justa y que promueva el bienestar de todos: es, pues, instrumental para el bien de los individuos, que sigue siendo el objeto final de la vida en sociedad (Argañoda, 2011, p. 9).

Desde un enfoque institucionalista, puede interpretarse como esa estabilidad que debe existir a través del tiempo para lograr un bien común entre la sociedad, el respeto por los derechos fundamentales y la mejora de la calidad de vida, objetivos fundamentales del Estado moderno (Peters, 1999), sumado de nuevo con el objetivo garantista del Estado social de derecho, el institucionalismo se pronuncia sobre las causas y consecuencias de las instituciones políticas y adopta los valores políticos de la democracia liberal (Marsh \& Stoker, 1995).

Esta democracia liberal se compone de un aspecto fundamental para comprender por qué los Estados modernos tienden a llevar al máximo la defensa de las libertades individuales dejando de lado la colectividad; esto es, a las instituciones siempre les importará más el afectar el comportamiento individual para poder cumplir sus objetivos (Peters, 1999).

Sin embargo, cuando se habla de bien común el término puede variar ya sea axiológicamente o a partir de la concepción ciudadana que se tiene del mismo. Por un lado se puede aducir a un tipo de empoderamiento social que se gesta a partir de los escenarios donde el individuo reconoce colectivamente un interés personal y que a su vez puede generar una movilización colectiva al identificarse con la causa; por otro, como la respuesta del Estado a lo que considera "bien común" para la sociedad diseñando acciones que apunten a resolver esas necesidades bajo un marco de intereses gubernamentales como respuesta a las políticas estatales.

La participación ciudadana en los asuntos públicos debe constituir uno de los ejes centrales para generar ese valor público. Para ello es necesario que este se encuentre incorporado en las decisiones gubernamentales y principalmente por las acciones que las instituciones estatales generan hacia los ciudadanos; por lo que el acompañamiento de las instancias en el proceso de participación ciudadana permite aumentar dicha legitimización de las respuestas estatales ya que empodera a las comunidades sobre los tipos de planes, programas y proyectos desarrollar.

\section{A modo de conclusión}

Una participación social incluyente implica conocer los programas, la estructura, los resultados y las consecuencias que tiene la política pública en nuestra sociedad; no 
se trata solo de exigir el resguardo de un bien público o de que se tomen medidas coyunturales para subsanar el problema; se trata de aplicar un valor a lo que aún es público para la sociedad.

Por otra parte, las políticas públicas no son la única herramienta con la cual el Estado hace visibles sus gestión, pero es una de las pocas que permiten un constante monitoreo y seguimiento de los resultados, que parten de un reconocimiento de la participación ciudadana como elemento integrador y sinérgico de espacios, actores e instancias para una óptima administración.

Cuando existe una adecuada divulgación de las demandas, como un mecanismo de canalización entre el Gobierno y la ciudadanía, se genera legitimidad en la base social y conciencia sobre el seguimiento que debe tener una política pública. No es solo decidir e implementar; es conocer cuál es el papel que está desarrollando cada agente que interviene en el desarrollo de la misma, es cerciorarse de que las demandas que generaron la necesidad de esta política estén siendo mitigadas y focalizadas en lo que realmente exige la sociedad.

Así mismo, es necesario que se visibilicen las políticas públicas en la comunidad en la que se va a implementar el beneficio otorgado, pues en ocasiones se presenta un desconocimiento sobre las acciones que se ejecutan desde el Gobierno, lo que restringe su participación en el seguimiento y en el valor de lo público que implica la actuación de recursos físicos y financieros.

Entre tanto, la cohesión social como elementos en el empoderamiento ciudadano de los asuntos públicos debe partir por las herramientas como la socialización y la divulgación, que le permite a las instituciones generar en la ciudadanía un reconocimiento por las acciones que desarrollan dentro del marco dela gobernabilidad; de esta manera se inserta al ciudadano como veedor de los recursos públicos.

Para generar valor público en las políticas públicas se debe tener en cuenta la innovación institucional. Esta comprendida como un eje articulador entre el ciudadano y las instituciones que permite crear estrategias que introduzcan herramientas en la esfera social teniendo como finalidad incentivar la participación en las decisiones públicas.

En conclusión, no solo se trata de los espacios para que la ciudadanía se empodere de la participación como algo condicionado; se trata de contar con nuevos escenarios para la construcción de identidades ciudadanas ya que suele pasar que las personas no participan o son indiferentes a las políticas públicas porque no tienen el tiempo suficiente o no se identifican con la institucionalidad, por lo que simplemente dejan la decisiones a una minoría de ciudadanos que terminan siendo mayoría en términos de decisiones colectivas. 


\section{Referencias bibliográficas}

Aguilar, L. F. (2009). Marco para el análisis de las políticas públicas. En F. Mariñez \& V. Garza, Política pública y democracia en América Latina. Del análisis a la implementación. (pág. 14). México, D. F.: Porrúa.

Argañoda, A. (2011). El Bien Común. Madrid, España: Universidad de Navarra.

Bertucci, G. (2005). Gobierno digital y valor público. Organización de Naciones Unidas.

Blaug, R. a. (2006). "Heritage, democracy and public value. In: Capturing the public value of heritage". English Heritage, Swindon, pp. 25-26.

Camou, A. (2001). Los desafíos de la gobernabilidad. Estudio preliminar y compilación. México: Plaza y Valdés.

Canto, M. (2008). Gobernanza y participación ciudadana en las políticas públicas frente al reto del desarrollo. Política y Cultura, $N^{o} 30$.

Carrillo, E. y Tamayo, M. (2005). La formación de la Agenda pública. Foro Internacional .

Conejero, E. (2014). Valor público: Una aproximación Conceptual. 3CEmpresa, pp. 30-41.

Cunill, N. (mayo - junio de 1995). El enfoque de de los Derechos Humanos en las políticas públicas: Ideas para un debate. CLAD Reforma y Democracia No 4 .

Giménez, C., \& Valente, X. (2010). El enfoque de los derechos humanos en las políticas públicas: ideas para un debate en. Cuadernos del CENDES, vol. 27, núm. 74, mayo-agosto, pp. 51-80.

Graglia, J. (2012). En la Búsqueda del bien común. Buenos Aires: Konrad Adenauer.

Güendel, L. (2000). La política pública y la ciudadanía desde el enfoque de los derechos humanos. La búsqueda de una nueva utopía. En S. Reuben, Política Social: Vínculo entre Estado y Sociedad. San José de Costa Rica: UCR, pp. 169-218.

Guillen, A. K. (2009). Origen, espacio y niveles de participación ciudadana . Daena: International Journal of Good Conscience, pp. 179-193.

Marsh, D., \& Stoker, G. (1995). Teorías y métodos de la Ciencia Política. Madrid España: Alianza Editorial S.A.

Merino, M. (1995). La participación ciudadana en la democracia. México : Instituto Federal Electoral. 
Mujica, P. (2010). La igualdad Política: El Significado Actual de la Participación Ciudadana. Chile: RIL.

Nohlen, D. (2004). Sistemas electorales y partidos políticos. México: Fondo de Cultura Económica.

Peters, G. (1999). El nuevo institucionalismo, Teoría institucional en ciencia política. Barcelona - España: Gedisa editorial.

Roth, A.-N. (2002). Políticas Públicas. Formulación, implementación y evaluación. Bogotá: Aurora.

Uvalle, R. (2005). Ciudadanía y Administración pública. En J. León, \& J. C. Ramírez, Los ciudadanos de Cara al Siglo XXI (págs. 143-169). México: México: Universidad Autónoma del Estado de México, Facultad de Ciencias Políticas y Administración Pública.

Vicepresidencia de la República de Colombia; observatorio del programa presidencial de derechos humanos y DIH. (2009). El desafio de la ciudadanía. Bogotá: impresol Ediciones.

Villarreal, M. T. (2009). Participación ciudadana y políticas públicas. XXVII Congreso de la Asociación Latinoamericana de Sociologia "Latinoamericana interrogada". Buenos Aires, Argentina. 
